\title{
Desenvolvimento de Oidium neolycopersici em genótipos do gênero Lycopersicon
}

\author{
María Isabel Balbi-Peña*1, Kátia Regina Freitas Schwan-Estrada, José Renato Stangarlin²; João Batista Tolentino \\ Júnior $^{1}$
}

1Departamento de Agronomia, Universidade Estadual de Maringá - UEM, CEP 87020-900, Maringá, PR, e-mail: mariabalbi@hotmail.com; ${ }^{2}$ Centro de Ciências Agrárias, Universidade Es tadual do Oes te de Paraná - Unioes te, Campus de Marechal Cândido Rondon, Cx. Pos tal 91, CEP 85960-000, Marechal Cândido Rondon, PR. * Parte da tese de doutorado do primeiro autos. Universid ade Estadual de Maringá, Maringá, PR. Autor para correspondência: Maria Isabel Balbi-Peña (mariabalbi@hotmail.com)

Data de chegada: 15/09/2008. Aceito para publicação em: 14/07/2009.

\section{RESUMO}

Balbi-Peña M.I.; Schwan-Estrada, K.R.F.; Stangarlin, J.R.; Tolentino Júnior, J.B. Desenvolvimento de Oidium neolycopersici em genótipos do gênero Lycopersicon. Summa Phytopathologica, v.36, n.1, p.35-39, 2010.

O oídio, causado pelo fungo Oidium neolycopersici, é uma doença comum do tomateiro, sobretudo em condições de cultivo protegido. Para esclarecer a natureza da resistência a oídio avaliou-se o processo de infecção, através da histopatologia em diferentes genótipos de to mateiro: CNPH 416, CNPH 423, CNPH 1287 (Lycopersicon hirsutum), CNPH 0081 (L. esculentum var. cerasiforme), cv. Santa Cruz Kada e cv. Santa Clara (L. esculentum). Para isso, três discos foliares (da $3^{\mathrm{a}}, 4^{\mathrm{a}}$ e $5^{\mathrm{a}}$ folha "verdadeira") de cada planta com $5-7$ folhas verdadeiras foram cortados e colocados em placas de Petri contendo ágar-água. Os discos foram inoculados a partir de micélio esporulante fresco desenvolvido em tomateiro suscetível e incubados a $19-22^{\circ} \mathrm{C}, 4000 \mathrm{~lx}$ e fotoperíodo de $12 \mathrm{~h}$. Os discos foram clareados em etanol aquecido e examinados microscopicamente 19 h, 8 e 9 dias após-inoculação para avaliar desenvolvimento de tubo germinativo, esporulação e severidade da doença, respectivamente. A germinação dos conídios sobre o tecido foliar não apresentou diferenças entre genótipos. A formação de hifa secundária, apressórios e haustórios por conídio germinado foram menores nos genótipos CNPH 1287 e 423, que também apresentaram menor esporulação e severidade da doença. Os genótipos de L. esculentum e L. esculentum var. cerasiforme apresentaram maior suscetibilidade ao oídio e CNPH 416 apresentou suscetibilidade intermediária. Assim, observou-se que a resistência a oídio de CNPH 1287 e 423 ficou evidenciada já desde as 19 horas após a inoculação, principalmente pela menor porcentagem de hifa secundária e número de apressórios e haustórios formados quando comparados com os genótipos suscetíveis.

Palavras-chave adicionais: oídio de tomateiro, tomateiro, resistência, formação de apressório, formação de haustório, histopatologia.

\section{ABSTRACT}

Balbi-Peña M.I.; Schwan-Estrada, K.R.F.; Stangarlin, J.R.; Tolentino Júnior, J.B. Development of Oidium neolycopersici on Lycopersicon genotypes. Summ a Phytopathologica, v.36, n.1, p.35-39, 2010.

Tomato powdery mildew, caused by Oidium neolycopersici, is a common disease of tomato, especially in greenhouse conditions. To investigate the nature of powdery mildew resistance, we studied the histopathology of the infection process in six different tomato genotypes: CNPH 416, CNPH 423, CNPH 1287 (Lycopersicon hirsutum), CNPH 0081 (L. esculentum var. cerasiforme), cv. Santa Cruz Kada e cv. Santa Clara (L. esculentum). Leaf discs of the $3^{\text {rd }}, 4^{\text {th }}$ e $5^{\text {th }}$ leaves from plants with 5-7 true leaves were placed on water agar in Petri dishes, inoculated using fresh sporulating mycelium of tomato powdery mildew and incubated at $19-22^{\circ} \mathrm{C}, 4000 \mathrm{~lx}$ and $12 \mathrm{~h}$ photoperiod. After clearing with boiling ethanol, the discs were microscopically examined at $19 \mathrm{~h}, 8$ and 9 days post inoculation to evaluate germ tube development, sporulation and disease severity. Conidial germination on foliar tissue was similar in all genotypes. Secondary hypha, appresoria and haustoria per germinated conidia were lowest in CNPH 1287 and 423, which also exhibited the lowest sporulation and disease severity. L. esculentum and L.esculentum var. cerasiforme ge notypes showed the highest mildew susceptibility and CNPH 416 showed intermediate susceptibility. Powdery mildew resistance of CNPH 1287 and CNPH 423 was already evident at 19 hours after inoculation based upon the lower percentage of secondary hypha, appresoria and haustoria observed than in the susceptible ones.

Keywords: tomato powdery mildew, tomato, resistance, appresorium formation, haustorium formation, histopathology.

Oídio do tomateiro, causado por Oidium neolycopersici L. Kiss tem causado problemas sérios na cultura nos últimos anos, principalmente sob condições de cultivo protegido $(2,6,9,11,16)$. O patógeno afeta a superfície adaxial das folhas, pecíolos, caule e cálices, com presença de micélio e estruturas de frutificação as sexuada do fungo conferindo o característico aspecto pulvurulento de cor branca a cinza. Em estágios mais avançados, os tecidos subadjacentes apresentam clorose e, finalmente, necrose. As infecções severas conduzem às plantas a senescência prematura, desfolha e redução do número e tamanho de frutos $(11,16,20)$.

$\mathrm{O}$ us o de cultivares resis tentes constitui a alternativa mais eficiente e segura para o controle da doença, pois reduz os custos de produção e evita danos à s aúde humana e ao ambiente. A obtenção de fontes de resistência entre os cultivares de tomateiro não tem levado a muito sucesso, o que gera a necessidade da procura entre espécies de Lycopersicon selvagens. "Screening" intensivo tem identificado 
diferentes fontes potenciais de resistência em acessos de L. hirsutum, L. chilense, L. parviflorum, L. peruvianum, L. pimpinellifolium, $L$. esculentum var. cera siforme e $L$. pennellii $(3,4,5,12,13,14,16)$.

Embora mecanismos de defesa passivos ou pré-formados (espessura da cutícula, presença de tricomas, entre outros) possam prevenir a infecção, por vezes, as plantas mostram respostas ativas ao ataque de patógenos, como transcrição de genes e formação de produtos de defes a, com o objetivo de retardar o desenvolvimento do patógeno ou levar à morte da célula vegetal $(16,18)$. A expressão de resistência pode ser determinada em vários níveis, desde populações de plantas até o estudo de planta individual, através de histologia e respostas moleculares. Ahisto logia da interação patógeno-hospedeiro é um recurso eficiente no estudo dos processos de infecção, ajuda a esclarecer os eventos de pré-penetração, penetração e colonização do hospedeiro, e possibilita o entendimento da fisiologia da interação e os mecanis mos de resistência do hospedeiro (1).

Existem estudos focados na resistência de tomateiro e de espécies aparentadas a Oidium neolycopersici $(4,14,16,17,19)$ onde foram estudados aspectos como: germinação de conídios na superfície do hospedeiro, comprimento de tubos germinativos, formação de apressórios e haustórios, formação de papilas, respostas de hipersensibilidade, formação de conidióforos, esporulação, produção de espécies reativas de oxigênio (ERO's) e de atividade de enzimas relacionadas ao metabolismo de ERO's.

O presente trabalho teve como objetivo estudar as etapas iniciais do processo de infecção de $O$. neolycopersici, a esporulação e a correspondente severidade no hospedeiro suscetível vs. resistente, buscando detectar diferentes es tratégias de resistência.

\section{MATERIALE MÉTODOS}

\section{Patógeno e material vegetal}

$\mathrm{O}$ is olado de $O$. neolycopersici empregado foi obtido a partir de tomateiros doentes provenientes do campo experimental da Universidade Estadual do Oeste de Paraná (Unioeste), campus de Marechal Cândido Rondon (Paraná) e mantido em plantas de genótipo com alta suscetibilidade (Santa Cruz Kada), a $19-22^{\circ} \mathrm{C}, 4000 \mathrm{~lx}$ e $12 \mathrm{~h}$ de fotoperíodo. Foram utilizados seis genótipos de Lycopersicon spp. com diferentes níveis de resistência a $O$. neolycopersici. Os acessos de Lycopersicon esculentum var. cerasiforme e $L$. hirsutum foram cedidos pelo Centro Nacional de Pesquisa de Hortaliças (CNPH) da Empresa Brasileira de Pesquisa Agropecuária (EMBRAPA), Brasília - DF, Brasil. As sementes dos diferentes genótipos foram semeadas em bandejas contendo sub strato comercial para produção de mudas. Aos
45 após semeadura foram transplantados para vasos plásticos com capacidade para 1,5 L (uma planta por vaso) contendo uma mis tura deste substrato, solo e areia esterilizados (2:1:1 v/v) e mantidos sob condições de casa de vegetação.

\section{Inoculação e incubação de discos foliares}

Aos 63 dias após o transplantio, quando as plantas apresentavam de cinco e sete folhas totalmente desenvolvidas, três discos com 11 $\mathrm{mm}$ de diâmetro foram retirados do folíolo terminal da $3^{\mathrm{a}}, 4^{\mathrm{a}}$ e $5^{\mathrm{a}}$ folhas. Os discos foliares foram colocados em placas de Petri contendo ágar-água $\left(15 \mathrm{~g} \mathrm{~L}^{-1}\right)$ com a face adaxial voltada para cima. A inoculação com $O$. neolycopersici, foi realizada através de pequenas batidas com folhas de tomate cobertas (80-100\%) por micélio esporulante fresco $(15,16)$. O número médio de conídios inoculados sobre os discos foliares foi de 39,7 esporos $\mathrm{mm}^{-2}$. Na sequiência após a inoculação, as placas de Petri foram fechadas com filme plástico e incubadas em câmara de crescimento a $19-22^{\circ} \mathrm{C}$, intensidade de luz $4000 \mathrm{~lx}$ e fotoperíodo de $12 \mathrm{~h}$, sendo o período com luz iniciado no momento da colocação das placas na câmara de crescimento.

\section{Observação microscópica do processo de infecção de $O$. neolycopersici}

Os discos foliares dos genótipos foramexaminados decorridos 19 h, 8 e 9 dias de incubação. Para tanto, procedeu-se a descoloração dos mesmos pela imersão em etanol $\left(92^{\circ}\right)$ aquecido a $78^{\circ} \mathrm{C}$ e conservados em glicerol $50 \%$ até observação. Os discos foram montados em lâminas de microscopia com lactofenol-azul de algodão e observados sob microscópio de luz Leitz Diaplan. Às 19 horas pós-inoculação (hpi) determinou-se o percentual de germinação dos conídios através da contagem daqueles que apresentavam tubos germinativos (contagem de 100 conídios em cada disco foliar). O desenvolvimento do fungo foi determinado através do número de tubos germinativos por conídio, comprimento destes e presença de apressório e haustórios, sendo essas características de desenvolvimento registradas em 20 conídios germinados por disco de modo a obter-se 300 conídios para cada genótipo.

Aos oito dias pós-inoculação (dpi) determinou-se a esporulação do patógeno nos discos foliares, quando os conídios foram removidos mediante a aplicação cuidadosa de pequenos pedaços $(1 \mathrm{x} 1 \mathrm{~cm}) \mathrm{de}$ fita adesiva transparente sobre os discos foliares e posteriormente transferidos para lâmina de microscopia com lactofenol-azul de algodão para observação e contagem de esporos ao microscópio de luz.

\section{Severidade de infecção}

O percentual do grau máximo de infecção (ID) foi determinado aos

Tabela 1. Identificação, origem e nível de resistência/susceptibilidade dos genótipos de Lycopersicon empregados na avaliação do processo de infecção por Oidium neolycopersici.

\begin{tabular}{llc}
\hline $\begin{array}{l}\text { Genótipo (cultivar, acesTabela 1. Identificação, origem e nível de resistência/susceptibilidade } \\
\text { dos genótipos de Lycopersicon empregados na avaliação do processo de infecção por Oidium } \\
\text { neolycopersici.so) }\end{array}$ & Origem & $\begin{array}{c}\text { Resistência/ } \\
\text { suscetibilidade }\end{array}$ \\
\hline $\begin{array}{l}\text { Lycopersicon esculentum cv. Santa Cruz Kada } \\
\text { Lycopersicon esculentum cv. Santa Clara }\end{array}$ & Comercial & Suscetível \\
Lycopersicon hirsutum (CNPH $416-$ PI 126445) & Comercial & Suscetível \\
Lycopersicon hirsutum (CNPH $423-$ PI 134417) & CNPH & Resistente \\
Lycopersicon hirsutum (CNPH 1287 - PI 126445) & CNPH & Resistente \\
Lycopersicon esculentum var. cerasiforme (CNPH 0081 - Silvestre de Felixlândia) & CNPH & Resistente \\
\hline
\end{tabular}

${ }^{1}$ CNPH - Centro Nacional de Pesquisa de Hortaliças da Empresa Brasileira de Pesquisa Agropecuária (EMBRAPA), Brasilia - DF, Brasil. 
nove dpi através da observação macroscópica das estruturas fúngicas nos discos. A severidade foi determinada empregando-se a escala de Kashimoto et al. (7) de acordo com a porcentagem de superfície foliar coberta pelo fungo: $0=$ ausência de sinais do patógeno, $1=$ sinais em menos de $25 \%$ da área, $2=$ sinais em menos de $25-50 \%$ da área, $3=$ sinais em $51-75 \%$ da área, 4 = sinais em mais de $76 \%$ da área. A severidade em cad a planta foi determinada us ando a seguinte fórmula:

$$
D(\%)=\frac{\sum \text { notas }}{\text { número de dis } \cos \times \text { nota máxima da escala }} \times 100
$$

\section{Estatística e delineamento experimental}

O delineamento experimental utilizado foi inteiramente casualizado, com seis tratamentos e cinco repetições. Cada parcela experimental foi representada por uma placa de Petri contendo três discos foliares, e a média dos três discos foi empregada na análise estatís tica. Foram realizados testes para homogeneidade da variância (teste de Levene, $\mathrm{p}=0,05$ ) e para normalidade dos erros (teste de Shapiro-Wilk, $\mathrm{p}=0,05$ ), e quando as pressuposições foram violadas, procedeu-se transformação dos dados. Foi realizada análise de variância e as médias foram comparadas pelo teste de Scott-Knott $(\mathrm{p}=0,05)$.

\section{RESULTADOS E DISCUSSÃO}

A forma e dimensão dos conídios de $O$. neolycopersici observados, coincidiram com os dados morfológicos relatados para a espécie (6, 8). Os conídios germinaram de modo uniforme na superfície foliar de todos os genótipos, com percentual médio de 54,5\%. Huang et al. (4) e Mieslero vá et al. (16) reportaram anteriormente que a resistência de tomateiro a $O$. lycopersicum não é devida a inibição da germinação de esporos.

Os conídios desenvolveram tubos germinativos primários com comprimento variável, mas sem diferenças significativas entre genótipos. Na parte terminal do tubo germinativo foi observado um apressório lobado (Fig. 1A). Com freqüência, sob o apressório, observou-se a formação de um haustório (Fig. 1B) e desenvolvimento de hifa secundária a partir do conídio ou do tubo germinativo primário (Fig 1C). Para os conídios que apresentavam hifa secundária foi detectado um haustório embaixo do apressório do tubo germinativo. Na coleta, realizada às 19 hpi, não foi observado a formação de apressório na hifa secundária. Para os diferentes genótipos não foram observadas diferenças para o comprimento da hifa secundária (dados não apresentados). Mieslerová et al. (16) em avaliações feitas 6, 24 e

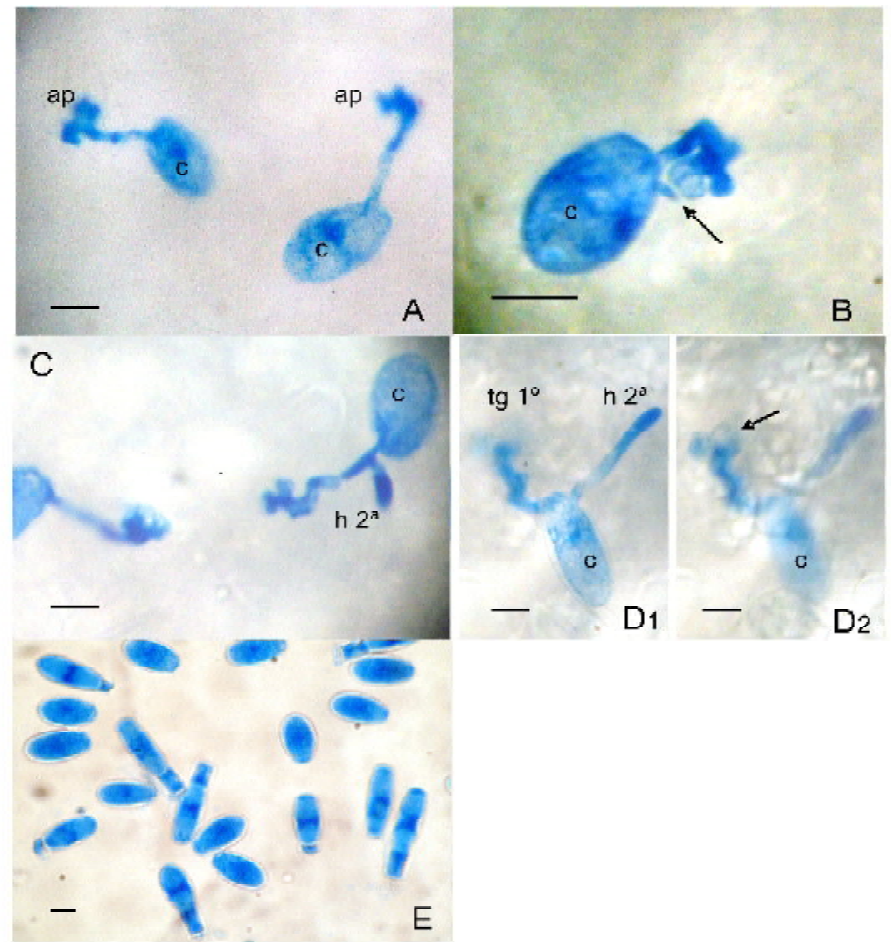

Figura 1. Microfotografias de conídios de O. neolycopersici em discos foliares de tomateiro 19 horas pós-inoculação. A: Apressório lobado (ap) B: Haustório (seta) desenvolvido embaixo do apressório. C: Conídio apresentando tubo germinativo primário com apressório e hifa secundária sem apressório. D1: Conídio com tubo germinativo primário com apressório e hifa secundária. D2: Mesmo conídio em plano focal inferior mostrando haustório (seta) sob apressório do $\operatorname{tg} 1^{\circ}$. E: Aspecto dos esporos aos 8 dias pós-inoculação no genótipo Santa Clara. Abreviações: $\mathrm{c}=$ conídio; $a \mathrm{p}=$ apressório $\operatorname{tg} 1^{\circ}=$ tubo germinativo primário; $\mathrm{h} 2^{\mathrm{a}}=$ hifa secundária. Barra $10 \mu \mathrm{m}$.

48 hpi observaram diferenças entre o comprimento dos tubos germinativos primários, secundários e terciários de conídios desenvolvidos em genótipos resistentes e suscetíveis de tomateiro.

Às 19 hpi, a maioria dos conídios já apresentava formação de apressórios no tubo germinativo primário, havendo só um genótipo (CNPH 1287) que se diferenciou dos outros por apresentar menor percentual de apressórios.

A presença de haustório não lobado sob o apressório foi observada nos diferentes genótipos, variando de 23 no CNPH 423 a 79,6\% no CNPH 0081. Foram observadas diferenças significativas entre genótipos quanto à freqüência de formação de haustórios às 19 hpi,

Tabela 2. Características do desenvolvimento dos conídios de O. neolycopersici em discos foliares de genótipos de tomateiro avaliados às 19 horas após inoculação (hpi): comprimento do tubo germinativo primário (tg $1^{\circ}$ ), formação de hifa secundária (h $2^{\mathrm{a}}$ ), comprimento do tubo germinativo primário mais hifa secundária $\left(\operatorname{tg} 1^{\circ}+\mathrm{h} 2^{\mathrm{a}}\right)$, formação de apressório e haustório

\begin{tabular}{|c|c|c|c|c|c|c|}
\hline Genótipos & $\operatorname{tg} 1^{\circ}(\mu \mathrm{m})$ & h $2^{a}$ & $\%$ & $\operatorname{tg} 1^{\circ}+h 2^{a}(\mu \mathrm{m})$ & Apressório(\%) & Haustório(\%) \\
\hline CNPH 1287 & $18,3 \mathrm{a}$ & 0,6 & $\mathrm{a}$ & 18,3 a & $74,5 \mathrm{a}$ & $28,2 \mathrm{a}$ \\
\hline CNPH 423 & 17,8 a & 3,0 & $\mathrm{a}$ & 22,4 a & $87,0 \quad b$ & $23,0 \mathrm{a}$ \\
\hline CNPH 416 & $20,2 \mathrm{a}$ & 9,5 & $\mathrm{~b}$ & $33,3 \quad b$ & $96,5 \mathrm{~b}$ & $67,3 \quad b$ \\
\hline Santa Clara & $20.9 \mathrm{a}$ & 7,0 & $\mathrm{~b}$ & 32,5 & $97,5 \mathrm{~b}$ & $65,5 \mathrm{~b}$ \\
\hline CNPH 0081 & $20,3 \mathrm{a}$ & 22,2 & $\mathrm{c}$ & 32,0 & $94,5 \mathrm{~b}$ & 79,6 \\
\hline Sta. Cruz Kada & $25,0 \mathrm{a}$ & 29,5 & $\mathrm{c}$ & 46,4 & $96,7 \mathrm{~b}$ & $66,1 \quad b$ \\
\hline $\mathrm{CV}(\%)$ & 19,2 & 55,7 & & 23,2 & 6,9 & 15,7 \\
\hline
\end{tabular}

Médias na coluna seguidas de mesma letra não diferem entre si pelo teste de Scott-Knott ao nível de $5 \%$ de probabilidade. 
Tabela 3. Esporulação de $O$. neolycopersici e severidade de oídio em discos foliares de genótipos de tomateiro avaliados aos oito e nove dias pós-inoculação, respectivamente.

\begin{tabular}{lcccccc}
\hline & \multicolumn{2}{c}{ Esporos/disco $\left(\mathbf{1 0}^{\mathbf{2}}\right)^{1}$} & \multicolumn{2}{c}{ Severidade da doença } \\
\cline { 2 - 7 } Genótipos & $\begin{array}{c}\text { Médias } \\
\text { origi nai }\end{array}$ & $\begin{array}{c}\text { Médias } \\
\text { transformadas }\end{array}$ & $\begin{array}{c}\text { Médias } \\
\text { originais }\end{array}$ \\
\hline CNPH 416 & 71,9 & 8,5 & a & 0 & a \\
CNPH 1287 & 97,3 & 9,9 & a & 0 & a \\
CNPH 423 & 137,3 & 11,7 & a & 0 & a \\
Santa Clara & 2498,4 & 50,0 & b & 13,3 & b \\
CNPH 0081 & 3867,8 & 62,2 & b & 38,3 & c \\
Sta. Cruz Kada & 6048,4 & 77,8 & c & 75,0 & d \\
\hline CV (\%) & \multicolumn{7}{c}{28,8} & & & 34,6
\end{tabular}

Médias na coluna seguidas de mesma letra não diferem entre si pelo teste de Scott-Knott ao nível de $5 \%$ de probabilidade.

${ }^{1}$ Para análise estatística os dados foram transformados em $\mathrm{y}=\sqrt{x}$. As médias originais foram obtidas pela operação inversa da transformação.

${ }^{2}$ Severidade da doença foi determinada para cada disco segundo a fórmula:ID $(\%)=[($ soma de todas as notas)/(número de discos avaliados x nota máxima da escala)] x 100. Notas: 0 (ausência de sintomas), 1 (sintomas emmenos de 25\% da área), 2 (sintomas emmenos de 25 $50 \%$ da área), 3 (sintomas em menos de 50-75\% da área), 4 (sintomas em mais de $76 \%$ da área).

sendo as menores frequiências nos CNPH 1287 e CNPH 423 e a maior no CNPH 0081. Kashimoto et al. (8) ao avaliarem o desenvolvimento de $O$. neolycopersici em cultivar suscetível de tomateiro em vários tempos pós-infecção, observaram a formação do haustório primário às $12 \mathrm{hpi} \mathrm{e} \mathrm{que} \mathrm{as} \mathrm{hifas} \mathrm{secundárias} \mathrm{desenvolveram-se} \mathrm{a} \mathrm{partir} \mathrm{do}$ conídio e posteriormente do apressório primário às 24 hpi. Matsuda et al. (14) verificaram que em acessos de $L$. hirsutum completamente resistentes ao oídio não se formaram haustórios funcionais e sugeriram que isto ocorreu devido à reação de hipersensibilidade ocorrida nas células epidérmic as invadidas pelo patógeno o que resultou em falha no estabelecimento da infecção a partir do conídio. Nas plantas de tomateiro suscetíveis, os conídios germinados e que formaram apressório penetraram as células com sucesso, formaram haustórios sem resposta de hipersensibilidade na célula atacada e originaram hifas secundárias para expandir suas colônias. Diferente dessa situação, Huang et al. (14) não observaram diferenças nos percentuais de formação de haustórios primários em genótipos suscetíveis e resistentes de diferentes espécies de Lycopersicon, mas sim em características como formação de haustório secundário, necrose induzida por haustório $1^{\circ}$ e $2^{\circ}$, número de hifas por conídio, número de apressórios por hifa, número de apressórios por conídio e esporulação às 65 hpi. Esses autores reportaram reação de hipersensibilidade nas avaliações tardias (65 hpi), quando a necrose das células atacadas determinou a supressão do haustório após sua formação. Vários autores consideram que a resposta de hipersensibilidade nas células epidérmicas seja a responsável pela resistência ao oídio em genótipos de tomateiro resistentes $(4,14)$. No presente trabalho não foi avaliada a resposta de hipersensibilidade nas células invadidas, mas a formação de haustórios e subseqüente formação de hifa secundária nas primeiras 19 hpi foi considerado um forte indicativo de resistência nos genótipos de $L$. hirsutum (CNPH 1287 e 423). Para o genótipo CNPH 416, o maior número de haustórios formados às 19 hpi pode ter sido seguido por resposta de hipersensibilidade nas células atacadas e responsável pela posterior degenerescência dos haustórios.

O patógeno produziu conídios não concatenados, o que confirma sua identificação como $O$. neolycopersici $(9,10)$. Foram observadas diferenças entre genótipos quanto a quantidade de esporos formados nos discos foliares na avaliação do oitavo dia pós-inoculação.

Essas diferenças permitem distinguir três grupos: o primeiro grupo comprendido pelos genótipos da espécie $L$. hirsutum com baixa esporulação; o segundo grupo compreendido pelo cv. Santa Clara e o L. esculentum var. cerasiforme, que apresentaram esporulação 31 vezes maior do que o primeiro grupo; e o terceiro grupo representado pela cv. Santa Cruz Kada a qual apresentou maior esporulação (cerca de 60 vezes maior do que o primeiro grupo). Segundo Huang et al. (4), o desenvolvimento de unidades de infecção nem sempre é detido quando as células epidérmicas, nas quais o haustório primário foi formado, se tornam necróticas. Quando o crescimento da hifa primária é bloqueado por necrose, novas hifas são usualmente formadas do outro lado do esporo. As hifas secundárias produzem novos apressórios e subsequentemente novos haustórios, embora, eventualmente, todos os haustórios possam estar associados com necrose de células epidérmicas e a infecção inibida completamente.

A menor esporulação observada para os genótipos de L. hirsutum, quando comparada a outras espécies foi coerente com a observação macroscópica dos sinais do patógeno nos discos foliares, onde nos genótipos de L. hirsutum não houve sintomas visíveis da doença. Lindhout et al. (13), em "screening" de 127 acessos de oito espécies selvagens de Lycopersicon reportaram que, macroscopicamente, a resistência a oídio foi caracterizada por uma frequiência de infecção muito baixa, crescimento micelial reduzido e ausência de esporulação.

Considerando-se os eventos iniciais e os mais tardios (esporulação e severidade da doença) da patogênese causada por $O$. neolycopersici em diferentes acessos de Lycopersicon selvagens, observa-se que os genótipos CNPH 1287 e 423 apresentaram comportamento diferente dos suscetíveis (CNPH 0081, cv. Santa Cruz Kada e cv. Santa Clara), principalmente quanto ao baixo número de haustórios e hifas secundárias formadas às 19 hpi, esporulação e severidade da doença aos 8 e 9 dpi, respectivamente.

\section{AGRADECIMENTOS}

Os autores agradecem ao CNPq pela concessão da bolsa de estudos a M.I. Balbi-Peña e pela bolsa de produtividade a K.R.F. SchwanEstrada e J. R. Stangarlin. Os autores agradecem também ao Dr. Leonardo Boiteux do Centro Nacional de Pesquisa de Hortaliças (CNPH) da EMBRAPA que gentilmente cedeu as sementes utilizadas no experimento.

\section{REFERÊNCIAS BIBLIOGRÁFICAS}

1. Araujo, J.C.A.; Matsuoka, K. Histopatologia da interação Alternaria solani e tomateiros resistente e suscetível. Fitopatologia Brasileira, Fortaleza, v. 29, p. :268-275, 2004.

2. Café Filho, A.C.; Coelho, M.V.S.; Souza, V.L. Oídios de Hortaliças. In: Stadnik, M.J.; Rivera, M.C. (Ed.) Oídios. Jaguariúna: Embrapa Meio Ambiente, 2001. p. 285-302.

3. Ciccarese F.; Amenduni M.; Schiavone D.; Cirulli M. Occurrence and inheritance of resistance to powdery mildew (Oidium lycopersici) in Lycopersicon species. Plant Pathology, London, v. 47, p. 417-419, 1998.

4. Huang, C.; Groot, T.; Meijer-Dekens, F.; Niks, R.; Lindhout, P. Hypersensitivity is the major mechanism of resistance to powdery mildew (Oidium lycopersicum) in Lycopersicon species. European Journal of Plant Pathology, Dordrecht, v. 104, p. 399-407, 1998.

5. Huang, C.; Hoefs-Van De Putte, P.M.; Haanstra-Van Der Meer, J.G.; Meijer-Dekens, F.; Lindhout, P. Characterization and mapping of resistance to Oidium lycopersicum in two Lycopersicon 
hirsutum accessions: evidence for close linkage of two Ol-genes on chromosome 6 of tomato. Heredity, Sheffield, v. 85, p. 511 520, 2000.

6. Jones, H.; Whipps, J.M.; Gurr, S.J. The tomato powdery mildew fungus Oidium neolycopersici. Molecular and Plant Pathology, London, v. 2, p. 303-309, 2001.

7. Kashimoto, K.; Same shima, T.; Matsuda, Y.; Nonomura, T.; Oichi, W.; Kakutani, K.; Nakata, K.; Kusakari, S.; Toyoda, H. Infectivity of a Japanese isolate of Oidium neolycopersici KTP-01 to a European tomato cultivar resistant to O. lycopersici. Journal of General Plant Pathology, Sapporo, v. 69, p. 406-408, 2003a.

8. Kashimoto, K.; Matsuda, Y.; Matsutani, K.; Sameshima, T.; Kakutani, K.; Nonomura, T.; Okada, K.; Kusakari, S.; Nakata, K.; Takamatsu, S.; Toyoda, H. Morphological and molecular characterization for a Japanese isolate of tomato powdery mildew $\mathrm{Oi}$ dium neolycopersici and its host range. Journal of General Plant Pathology, Sapporo, v. 69, p. 176-185, 2003b.

9. Kiss, L.; Cook, R.T.A.; Saenz, G.S.; Cunnington, J.H.; Takamatsu, S.; Pascoe, I.; Bardin, M.; Nicot, P.C.; Sato, Y.; Ross man, A.Y. Identification of two powdery mildew fungi, Oidium neolycopersici sp. nov. and $O$. lycopersici, infecting tomato in different parts of the world. Mycological Research, London, v. 105, p. 684-697, 2001.

10. Kiss, L.; Takamatsu, S.; Cunnington, J. H. Molecular identification of Oidium neolycopersicias the causal agent of the recent tomato powdery mildew epidemics in North America. Plant Di sease, St. Paul, v. 89, p. 491-496, 2005.

11. Kurozawa, C.; Pavan, M.A. Doenças do tomateiro. In: Kimati, H.; Amorim, L.; Bergamin Filho, A.; Camargo, L.E.A.; Rezende, J.A.M. (Ed.). Manual de fitopatologia: doenças das plantas cultivadas. São Paulo: Editora Agronômica Ceres, 2005. V. 2, p.607-626.

12. Li, C., Bai; Y., Jacobsen, E.; Visser, R.; Lindhout, P.; Bonnema, G. Tomato defense to the powdery mildew fungus: differences in expression of genes in susceptible, monogenic- and polygenic resistance responses are mainly in timing. Plant Molecular Biology, Dordrecht, v. 62, p. 127-140, 2006.

13. Lindhout, P.; Pet, G.; Van Der Beek, J.G. Screening wild Lycopersicon species for resistance to powdery mildew (Oidium lycopersicum). Euphytica, Wageningen, v. 72, p. 43-49, 1994.

14. Matsuda, Y.; Mori, Y.; Sakano, Y.; Nishida, M.; Tarumoto, K.; Nonomura, T.; Nishimura, H.; Kusakari, S; Toyoda, H. Screening of wild Lycopersicon species for resistance to japanese isolate of tomato powdery mildew Oidium neolycopersici. Breeding Sci ence, Tokyo, v. 55, p. 355-360, 2005.

15. Mieslerová, B.; Lebeda, A.; Chetelat, R.T. Variation in Response of Wild Lycopersicon and Solanum spp. against Tomato Powdery Mildew (Oidium lycopersici). Journal of Phytopathology, Berlin, v. 148, p. 303-311, 2000.

16. Mieslerová, B.; Lebeda, A.; Kennedy, R. Variation in Oidium neolycopersici development on host and non-host plant species and their tissue defence responses. Annals of Applied Biology, Warwick, v. 144, p. 237-248, 2004.

17. Mlíèková, K.; Luhová, L.; Lebeda, A.; Mieslerová, B.; Peè .P Reactive oxygen species generation and peroxidase activity during Oidium neolycopersici infection on Lycopersicon especies. Plant Physiology and Biochemistry, Paris, v. 42, p. 753-761, 2004 .

18. Pascholati, S.F.; Leite, B. Hospedeiro: mecanismos de resistência. In: Bergamin Filho, A.; Kimati, H.; Amorim, L. (Eds.). Manual de fitopatologia: princípios e conceitos. São Paulo: Agronômica Ceres, 1995. V. 1, p. 417-453.

19. Tománková, K.; Luhová, L.; Petøivalský, M.; Peè P.; Lebeda A Biochemical aspects of reactive oxygen species formation in the interaction between Lycopersicon spp. and Oidium neolycopersici. Physiological and Molecular Plant Pathology, London, v. 68 , p. 22-32, 2006.

20. Weht, S. Oídios del tomate. In: Stadnik, M.J., Rivera, M.C. (Org.). Oídios. Jaguariúna: Embrapa Meio Ambiente, 2001. p. 303-322. 